\title{
Professional Culture and Personality Traits of Hospital Pharmacists across Canada: A Fundamental First Step in Developing Effective Knowledge Translation Strategies
}

\author{
Meagen Rosenthal, Kevin W Hall, Jean-François Bussières, and Ross T Tsuyuki
}

\begin{abstract}
Background: Evidence for the value of pharmacists' interventions in the care of patients is strong and continues to grow, but the rate at which these new practice opportunities are being integrated into daily practice has not kept pace. The knowledge translation literature suggests that before effective change strategies can be implemented, a better understanding of the current environment must be obtained. Two important factors within the practice environment are the professional culture and personality traits of group members.

Objective: To gain insight, at a national level, into the culture of hospital pharmacy, using the Organizational Culture Profile, and into hospital pharmacists' personality traits, using the Big Five Inventory.

Methods: A cross-sectional survey of hospital pharmacists from across Canada was conducted intermittently over the period August 2012 to September 2013. The online survey contained questions about demographic characteristics and practice setting, as well as questions from the Organizational Culture Profile and Big Five Inventory. The survey link was distributed directly to hospital pharmacists or made available through provincial monthly newsletters. All data were analyzed descriptively and inferentially.

Results: In total, 401 surveys were returned. Descriptive analyses from the Organizational Culture Profile revealed that most respondents perceived value in the factors of supportiveness, competitiveness, and stability. Descriptive analyses from the Big Five Inventory revealed that respondents may have been more likely to exhibit behaviours in line with the trait of conscientiousness. Several significant subgroup differences were noted in relation to levels of education, regions of practice within Canada, years in practice, and proportion of time spent conducting clinical duties.

Conclusions: The results from this survey provide preliminary insight into the professional culture and personality traits of Canadian hospital pharmacists. It will be important to explore these findings in more depth to maximize the success of any future practice change initiatives.
\end{abstract}

Key Words: hospital pharmacy, professional culture, personality traits

\section{RÉSUMÉ}

Contexte : Le nombre de données solides montrant que les interventions des pharmaciens dans les soins des patients sont bénéfiques ne cesse de croître. Pourtant, l'intégration dans le quotidien de ces nouvelles occasions de pratique ne se fait pas au même rythme. D'après la littérature portant sur l'application des connaissances, il est nécessaire d'améliorer la compréhension du milieu d'aujourd'hui avant de pouvoir mettre en œuvre des stratégies de changement efficaces. Deux facteurs importants dont il faut tenir compte quant au milieu de pratique sont la culture professionnelle et les traits de personnalité des membres du groupe.

Objectif : Apprendre à mieux connaître, au niveau national, la culture de la pharmacie hospitalière à l'aide de l'outil de mesure de la culture organisationnelle, "Organizational Culture Profile ", et apprendre à connaître les traits de personnalité des pharmaciens hospitaliers à l'aide de l'outil sur les cinq traits centraux de la personnalité, "Big Five Inventory ".

Méthodes : Une enquête transversale auprès des pharmaciens hospitaliers du Canada a été réalisée de façon intermittente sur une période s'échelonnant d'août 2012 à septembre 2013. Le sondage en ligne contenait des questions sur les caractéristiques démographiques et le milieu d'exercice ainsi que des questions issues des outils « Organizational Culture Profile» et "Big Five Inventory ». Le lien vers le sondage a été donné directement aux pharmaciens hospitaliers ou il a été intégré à des bulletins d'information mensuels provinciaux. Toutes les données ont été analysées de façon descriptive et inférentielle.

Résultats : Au total, 401 sondages ont été retournés. Des analyses descriptives obtenues par l'intermédiaire de l'outil "Organizational Culture Profile " ont démontré que la plupart des répondants accordaient de la valeur aux facteurs de soutien, de compétitivité et de stabilité. Des analyses descriptives obtenues par l'intermédiaire de l'outil « Big Five Inventory " ont démontré que les répondants avaient plus de chances de présenter des comportements en lien avec le trait de la conscience professionnelle. Plusieurs importantes différences de sous-catégories ont été relevées en lien avec le niveau de scolarité, la région de la pratique au Canada, le nombre d'années de pratique et le temps passé à effectuer des activités cliniques.

Conclusions : Les résultats de ce sondage offrent un aperçu de la culture professionnelle et des traits de personnalité des pharmaciens hospitaliers du Canada. Il est important d'étudier plus en profondeur ces résultats afin de maximiser les chances de réussite des futures initiatives de changement de la pratique.

Mots clés : pharmacie hospitalière, culture professionnelle, traits de personnalité 


\section{INTRODUCTION}

$\mathrm{E}$ vidence for the value of pharmacists' interventions in patient care is strong and continues to grow. ${ }^{1-8}$ Patient care activities include developing relationships with patients and actively managing and taking responsibility for their medication therapy outcomes, developing care plans, and communicating with other members of the health care team. ${ }^{9}$ However, some would argue that the adoption and spread of these new practices has been too slow and remains incomplete. ${ }^{10-12}$ The knowledge translation literature ${ }^{13-17}$ argues that for sustained practice change to occur, a better understanding of current pharmacy context is needed.

According to the Promoting Action on Research Implementation in Health Services (PARiHS) framework, gaining insight into the pharmacy context demands that researchers and decision-makers develop an understanding of the "prevailing culture, the nature of human relationships as summarized through leadership roles and the organization's approach to routine monitoring of systems and services" (p. 152). ${ }^{13}$ Without question, an understanding of culture, leadership, and monitoring systems plays a key role in gaining insight into context; however, for the purposes of this project, the focus is on culture. Within this definition, the "culture" to which the PARiHS framework refers is organizational culture. The concept of organizational culture is not exclusive. ${ }^{18}$ Rather, it is possible, and even likely, that individuals simultaneously belong to multiple cultures, including organizational, professional, regional, and national cultures. ${ }^{18}$

An examination of the various definitions of "culture" used in the literature suggests that a standard, basic definition of the term, not specific to any particular organization or profession, may be applied. Regardless of whether a particular research endeavour is addressing organizational or professional culture, the definition traditionally focuses on a shared set of meanings. ${ }^{18-21}$ As such, for the purposes of this project, professional culture is defined broadly as the "patterns of [subjective] interpretation composed of meanings associated with various cultural manifestations, such as stories, rituals, formal and informal practices, jargon and physical arrangements" (p. 330). ${ }^{18}$ This means that culture can be understood as a part of the conceptual framework used by pharmacists to make sense of their everyday interactions.

The influence of professional culture on work-related behaviour has been investigated in studies involving probation officers, ${ }^{22}$ human resource specialists, ${ }^{23}$ and management accountants. ${ }^{24}$ This work identified correlations between culture and the success of rehabilitation efforts in relations between probation officers and offenders ${ }^{22}$; has revealed a focus on employee autonomy, rather than business outcomes ${ }^{23}$; and has shown miscommunications among different groups of accountants. ${ }^{24}$ Furthermore, descriptive examinations of the culture of health care professionals have been started for physicians, ${ }^{21}$ nurses, ${ }^{25}$ and social workers. ${ }^{26}$ The current work focuses on the professional culture of pharmacy, in an effort to first understand the components of that culture and then to gain preliminary insight into how that culture may interact with cultural antecedents, such as education and number of years in practice, to ultimately influence the daily behaviours of pharmacists.

A literature review examining the relationship between organizational culture and health care performance yielded no pharmacy-specific or general professional culture-measurement tools that could be used in the current study. ${ }^{27}$ As such, the shared aspects of the professional culture of pharmacy were examined with the Organizational Culture Profile. ${ }^{19}$ Although originally developed to measure organizational culture in a general sense, ${ }^{28}$ the Organizational Culture Profile has also been used to measure the aggregate culture of an organization from the perspective of leaders within the organization, as well as individual members' perceptions and values. ${ }^{29}$ It is this flexibility that has allowed for descriptive application of this tool in the current study.

The previous version of this tool was administered using an ipsative method, whereby facilitators assisted participants in completing the profile, ${ }^{28}$ and this version has been successfully used in health care settings. ${ }^{30}$ However, this approach to data collection is very labour intensive and limits access to larger samples. A 40-item version of the instrument developed by Sarros and others ${ }^{31}$ was used for the current study because it can be selfadministered, thereby allowing for a potentially larger sample of respondents. One possible limitation of this particular version of the instrument is that to date it has been used only for manager samples. $^{31}$

The instrument comprises 7 cultural factors, each of which is described in detail below: innovation, supportiveness, social responsibility, competitiveness, stability, performance orientation, and reward orientation. ${ }^{31}$ The reported reliability scores for these factors ranged from 0.66 for stability to 0.87 for supportiveness, with most reliability scores clustering between 0.74 and $0.80 .^{31}$ The degree to which a group perceives value in each of these factors is determined by scoring responses to a particular subset of the items.

As described by Sarros and others, ${ }^{31}$ groups that perceive value in being "quick to take advantage of opportunities", "risk taking”, and taking "individual responsibility" may score higher on the factor of innovation. Groups that perceive value in being "team and people oriented" and "sharing information freely" and that are "collaborative" may score higher on supportiveness. Groups that perceive value in being "reflective" and "having a good reputation" and a "clear guiding philosophy" may score higher on social responsibility. Groups that perceive value in being "achievement oriented", that "emphasize quality", and that value "being distinctive and different from other groups" may score higher on competitiveness. Groups that perceive value in being "calm" and "having low conflict" and a "sense of job security" may score higher on stability. Groups that perceive value in having "high expectations for performance" and "enthusiasm 
for their job" and that tend to be "results oriented" and "highly organized" may score higher on performance orientation. Groups that perceive value in being "fair", "providing opportunities for professional growth", and having "high pay and praise for good performance" may score higher on reward orientation.

While there has been debate about the nature of the relationship between culture and personality, ${ }^{32-34}$ the approach adopted for the current work assumes that culture and personality are independent factors that interact to produce a particular set of behaviours in individuals. ${ }^{34}$ As such, it is important to account for the personality of group members. However, the examination presented here is strictly descriptive, as there is no measure of how culture and personality may interact to produce certain behaviours. Rather, the independent interactions of cultural factors and personality traits with other variables are considered.

The most commonly recognized personality traits are those that constitute the Big Five Inventory: extraversion, agreeableness, conscientiousness, neuroticism, and openness. ${ }^{35-37}$ The extraversion trait describes behaviours such as being "energetic", "enthusiastic", "social", "assertive", "confident", and "ambitious". ${ }^{35}$ The agreeableness trait refers to behaviours such as being "altruistic", "cooperative", "willing to conform to group norms", and "displaying warmth and kindness". ${ }^{35}$ Conscientiousness includes the ability to "control impulses" so as to "facilitate goal-directed behaviour", the ability to "follow norms and rules", and "efficiency in planning, organizing and prioritizing tasks". ${ }^{35}$ Neuroticism (as opposed to emotional stability) describes behaviours associated with "feelings of anxiety", "nervousness", and "depression". People with higher scores for neuroticism may also display "self-consciousness" and be more "moody", "impulsive", and "stress-prone". ${ }^{35}$ Finally, people with higher scores on the "openness to experience" trait are likely to have a "wide, deep and complex level of experience in the world". ${ }^{35}$ Such people are also likely to be "knowledgeable", "perceptive", and "analytical", to "seek out new experiences", and to be more "artistic" and "investigative". ${ }^{35}$

The Big Five Inventory was chosen for use in this study because, unlike some other personality measurement tools, it is said to specifically measure traits, rather than personality states or preferences. ${ }^{35}$ Reliability scores for this instrument ranged from 0.79 for agreeableness to 0.87 for neuroticism, and the instrument has been validated in a relatively large North American sample. ${ }^{35}$ The Big Five Inventory is considered a short instrument, suitable for self-administration, based on 44 phrases measured on a 5-point Likert scale. ${ }^{35}$ As with the Organizational Culture Profile, primary scoring for the Big Five Inventory involves combining the Likert responses for specific subsets of the 44 phrases related to each of the identified personality traits.

The first objective of this study was to gain insight, at a national level, into the culture of hospital pharmacy in Canada, using the Organizational Culture Profile, and into the personality traits of Canadian hospital pharmacists, using the Big Five
Inventory. The second objective was to gain descriptive insight into possible interactions between cultural factors (identified by the Organizational Culture Profile) and the personality traits of pharmacist respondents (identified by the Big Five Inventory) and a number of demographic and practice-related variables.

\section{METHODS}

This cross-sectional study surveyed hospital pharmacists from across Canada. The study survey consisted of 3 sections. The first section contained basic demographic and practicesetting questions designed to gain insight into cultural antecedents (i.e., sex, education, province of practice, number of years in practice, and percentage of time spent performing clinical activities). The structure of these questions was based on a survey used in a previous study. ${ }^{38}$ Section 2 contained questions from the Big Five Inventory, and section 3 contained questions from the Organizational Culture Profile. A member of the research team translated the demographic questions, the practice-setting questions, and the Organizational Culture Profile questions into French for use in Quebec. An existing French-language version of the Big Five Inventory was used.

\section{Data Collection}

Both the English and French versions of the survey were administered online. A student research assistant identified and contacted provincial branches of the Canadian Society of Hospital Pharmacists for assistance with distribution of the link. The methods of distribution varied with each provincial branch's regulations. For example, some were able to distribute the link directly to members, while other branches placed the link, along with a short explanation of the study, in monthly newsletters. To improve response rates, members of the research team also directly contacted various individuals working in pharmacy departments across Canada to seek assistance with direct distribution. Data collection took place from August 2012 to September 2013; data collection was not continuous over this period, as there was a delay in access to the French version to allow time for translation of the survey instrument.

This study received ethics approval from the Health Research Ethics Board at the University of Alberta. The need for respondents to provide written informed consent was waived, and a statement at the beginning of the survey instrument informed respondents that completion and submission of the survey implied consent.

\section{Analysis}

In preparing and cleaning the data for analysis, the demographic and practice-setting questions were first examined descriptively. On the basis of this analysis, the education question was transformed into a variable called "highest level of education”. The categories of this variable were bachelor's degree in 
This single copy is for your personal, non-commercial use only.

For permission to reprint multiple copies or to order presentation-ready copies for distribution, contact CJHP at cjhpedit@cshp.ca

pharmacy (BScPharm or BSP), doctor of pharmacy degree (PharmD), hospital residency, Master of Clinical Pharmacy degree (MScPharm), and board of pharmacy specialization (BPS). The province in which the respondent was practising at the time of participation was transformed into "Canadian regions". The categories of this variable were Western Canada, Ontario, Quebec, and Atlantic Canada. No responses were received from any of the territories. The years-in-practice question was transformed into a variable called "years in practice by decade". The categories of this variable were 1-10 years, 11-20 years, 21-30 years, and 31 years or more.

Responses for the Organizational Culture Profile and the Big Five Inventory were analyzed using the scoring guidelines provided by the authors of the instruments. ${ }^{31,35}$ In each case, this scoring process yields mean values for each factor or trait. This analytic approach allows scores for factors and traits to be directly compared with demographic and practice-location variables. Preliminary characterization of these mean scores was achieved by comparison with previously published data. ${ }^{31,39}$ Notably, neither the Organizational Culture Profile nor the Big Five Inventory generates demonstrative measures of culture or personality. As such, it would be inappropriate to suggest that respondents' culture was innovative or that respondents' personality was extraverted, for example. Rather, the results from the Organizational Culture Profile are described as suggesting that respondents perceived value in the various factors, and results from the Big Five Inventory are used to describe respondents as being "possibly more likely to exhibit behaviours" in line with a particular trait. All reliability scores were calculated using the Cronbach $\alpha$ test.

The scores for the Organizational Culture Profile and the Big Five Inventory and the cultural antecedent variables were compared using analysis of variance (ANOVA). The effect size of the magnitude of any observed relationships was measured with the eta-squared $\left(\eta^{2}\right)$ test. Small, medium, and large effects were defined according to the following criteria: $\eta^{2} \leq 0.04$, $\eta^{2}>0.04$, and $\eta^{2}>0.36$, respectively. ${ }^{40}$ Because of the exploratory nature of this study, post hoc tests, including the Tukey and Games-Howell tests as appropriate, were used to determine the location of specific subgroup differences between means. ${ }^{41}$ All identified subgroup differences were measured using a 0.05 level of significance.

\section{RESULTS}

A total of 401 survey instruments were completed, representing 7\% of all hospital pharmacists in Canada (based on a population estimate of 5600 Canadian hospital pharmacists $\left.{ }^{42}\right)$. Most respondents were women (312 [78\%]), and 170 (42\%) had achieved a BScPharm or BSP degree as the highest level of education (Table 1). About one-third (121 [30\%]) of respondents practised in Ontario. The average number of years in
Table 1. Characteristics of Survey Respondents $(n=401)$

\begin{tabular}{|c|c|c|}
\hline Characteristic & $\begin{array}{r}\text { No } \\
\text { of Resp }\end{array}$ & $\begin{array}{l}\text { (\%) } \\
\text { ondents }\end{array}$ \\
\hline Sex & & \\
\hline Female & 312 & (78) \\
\hline Male & 86 & $(21)$ \\
\hline Data missing & 3 & (1) \\
\hline Highest level of $\epsilon$ & & \\
\hline BSCPharm or BSP & 170 & $(42)$ \\
\hline PharmD & 46 & (11) \\
\hline Hospital residency & 113 & (28) \\
\hline MScPharm & 59 & $(15)$ \\
\hline BPS & 9 & $(2)$ \\
\hline Data missing & 4 & (1) \\
\hline Region of Canad & & \\
\hline Western Canada & 109 & $(27)$ \\
\hline Ontario & 121 & (30) \\
\hline Quebec & 71 & (18) \\
\hline Atlantic Canada & 100 & $(25)$ \\
\hline Data missing & 0 & (0) \\
\hline Time in practice, & & \\
\hline $1-10$ years & 126 & (31) \\
\hline $11-20$ years & 114 & $(28)$ \\
\hline $21-30$ years & 91 & $(23)$ \\
\hline$\geq 31$ years & 64 & (16) \\
\hline Data missing & 6 & (1) \\
\hline Time spent perfo & $\%$ & \\
\hline $0-25$ & 144 & $(36)$ \\
\hline $26-50$ & 80 & $(20)$ \\
\hline $51-75$ & 98 & (24) \\
\hline $76-100$ & 77 & (19) \\
\hline Data missing & 2 & $(<1)$ \\
\hline
\end{tabular}

BPS = board of pharmacy specialization.

practice was 17 years (standard deviation [SD] 11). Most respondents spent no more than $50 \%$ of their time completing clinical duties.

On the Organizational Culture Profile, respondents' average scores were 3.05 out of 5 on innovation, 3.95 on supportiveness, 3.69 on social responsibility, 3.61 on competitiveness, 3.76 on stability, 3.89 on performance orientation, and 3.32 on reward orientation (Table 2). On the Big Five Inventory, respondents' average scores were 3.11 out of 5 on extraversion, 3.75 on agreeableness, 3.93 on conscientiousness, 2.53 on neuroticism, and 3.32 on openness (Table 2). Table 2 compares these data with the means for comparator samples. In the current study, reliability scores for responses on the Organizational Culture Profile ranged from 0.48 for stability to 0.73 for innovation and on the Big Five Inventory from 0.77 for openness to 0.88 for extraversion.

Analyses of the Organizational Culture Profile factors and Big Five Inventory traits in relation to the identified cultural antecedents revealed a number of significant interactions. There was a significant association between highest level of education 
This single copy is for your personal, non-commercial use only.

For permission to reprint multiple copies or to order presentation-ready copies for distribution, contact CJHP at cjhpedit@cshp.ca

Table 2. Scores for Study Sample and Population

\begin{tabular}{lcc} 
& \multicolumn{2}{c}{ Mean Score \pm SD } \\
\cline { 2 - 3 } Factor or Trait & Study Sample & Comparator Sample* \\
\hline Organizational Culture Profile & & \\
Innovation & $3.05 \pm 0.77$ & $3.50 \pm 0.91$ \\
Supportiveness & $3.95 \pm 0.63$ & $3.70 \pm 0.90$ \\
Social responsibility & $3.69 \pm 0.56$ & $3.93 \pm 0.74$ \\
Competitiveness & $3.61 \pm 0.58$ & $3.37 \pm 0.65$ \\
Stability & $3.76 \pm 0.50$ & $3.46 \pm 0.72$ \\
Performance orientation & $3.89 \pm 0.62$ & $4.02 \pm 0.71$ \\
Reward orientation & $3.32 \pm 0.66$ & $3.61 \pm 0.90$ \\
\hline Big Five Inventory & & $3.25 \pm 0.90$ \\
Extraversion & $3.11 \pm 0.85$ & $3.82 \pm 0.68$ \\
Agreeableness & $3.75 \pm 0.85$ & $3.73 \pm 0.71$ \\
Conscientiousness & $3.93 \pm 0.70$ & $3.13 \pm 0.86$ \\
Neuroticism & $2.53 \pm 0.71$ & $3.90 \pm 0.69$ \\
Openness & $3.32 \pm 0.59$ & \\
SD $=$ standard deviation. & & \\
*Comparator samples were taken from the literature: a sample of managers for the \\
Organizational Culture Profile ${ }^{31}$ and the general population for the Big Five Inventory.
\end{tabular}

and scores on the Organizational Culture Profile factors of innovation $\left(F_{1,4}=5.85, p<0.001, \eta^{2}=0.06\right)$ and competitiveness $\left(F_{1,4}=4.07, p<0.001, \eta^{2}=0.04\right)$. A significant association was also noted between highest level of education and scores on all of the Big Five Inventory traits: extraversion $\left(F_{1,4}=26.87, p<0.001, \eta^{2}=0.22\right)$, agreeableness $\left(F_{1,4}=60.16\right.$, $\left.p<0.001, \eta^{2}=0.38\right)$, conscientiousness $\left(F_{1,4}=40.00, p<0.001\right.$, $\left.\eta^{2}=0.29\right)$, neuroticism $\left(F_{1,4}=2.81, p<0.05, \eta^{2}=0.03\right)$, and openness $\left(F_{1,4}=17.34, p<0.001, \eta^{2}=0.15\right)$.

A significant association was noted between Canadian region and scores on the Organizational Culture Profile factors of innovation $\left(F_{1,3}=11.06, p<0.001, \eta^{2}=0.08\right)$, supportiveness $\left(F_{1,3}=6.37, p<0.001, \eta^{2}=0.05\right)$, social responsibility $\left(F_{1,3}=5.14, p<0.001, \eta^{2}=0.04\right)$, and competitiveness $\left(F_{1,3}=8.55, p<0.001, \eta^{2}=0.06\right)$. A significant association was observed between Canadian region and scores on all of the Big Five Inventory traits: extraversion $\left(F_{1,3}=55.97, p<0.001\right.$, $\left.\eta^{2}=0.30\right)$, agreeableness $\left(F_{1,3}=178.33, p<0.001, \eta^{2}=0.57\right)$, conscientiousness $\left(F_{1,3}=102.29, p<0.001, \eta^{2}=0.44\right)$, neuroticism $\left(F_{1,3}=9.20, p<0.001, \eta^{2}=0.07\right)$, and openness $\left(F_{1,3}=37.07, p<0.001, \eta^{2}=0.22\right)$.

A significant association was also noted between number of years in practice (by decade) and scores on the Organizational Culture Profile factor of competitiveness $\left(F_{1,3}=3.90, p<0.001\right.$, $\left.\eta^{2}=0.03\right)$ and the Big Five Inventory trait of conscientiousness $\left(F_{1,3}=2.70, p<0.05, \eta^{2}=0.02\right)$. Finally, there was also a significant association observed between time spent performing clinical activities and scores on the Big Five Inventory traits of agreeableness $\left(F_{1,4}=4.52, p<0.001, \eta^{2}=0.04\right)$ and conscientiousness $\left(F_{1,3}=4.30, p<0.001, \eta^{2}=0.03\right)$.

The complete results of the post hoc tests are presented in Tables 3 and 4.

\section{DISCUSSION}

When the mean scores for the Organizational Culture Profile from the sample of Canadian hospital pharmacists were compared with those for a sample of managers, hospital pharmacists scored higher on the factors of supportiveness, competitiveness, and stability (Table 2). As such, hospital pharmacists may perceive greater value in being team- and people-oriented, in sharing information freely, and in being collaborative ("supportive"). ${ }^{19}$ Hospital pharmacists may also perceive greater value in being achievement-oriented, emphasizing quality, and being distinctive and different from other groups ("competitive"). ${ }^{19}$ Furthermore, hospital pharmacists may perceive greater value in being calm, having low conflict, and having a sense of job security ("stable"). ${ }^{19}$

Comparing results for Canadian hospital pharmacists with general population means on the Big Five Inventory suggested that hospital pharmacists may be more likely to exhibit behaviours in line with the trait of conscientiousness. That is, they may be more able to behave in ways to control impulses and thus facilitate goal-directed behaviour, to follow norms and rules, and to be efficient in planning, organizing, and prioritizing tasks ("conscientiousness"). 35

Examination of the relationship between the Organizational Culture Profile and Big Five Inventory and the cultural antecedents suggested that hospital pharmacists' level of education, region of practice in Canada, number of years in practice, and time spent conducting clinical activities all influenced the manifestation of factors and traits. Furthermore, post hoc testing suggested the possibility of important subgroup differences within the larger profession of pharmacy.

This study had a number of important limitations. First, the survey response rate was low. However, an examination the most 


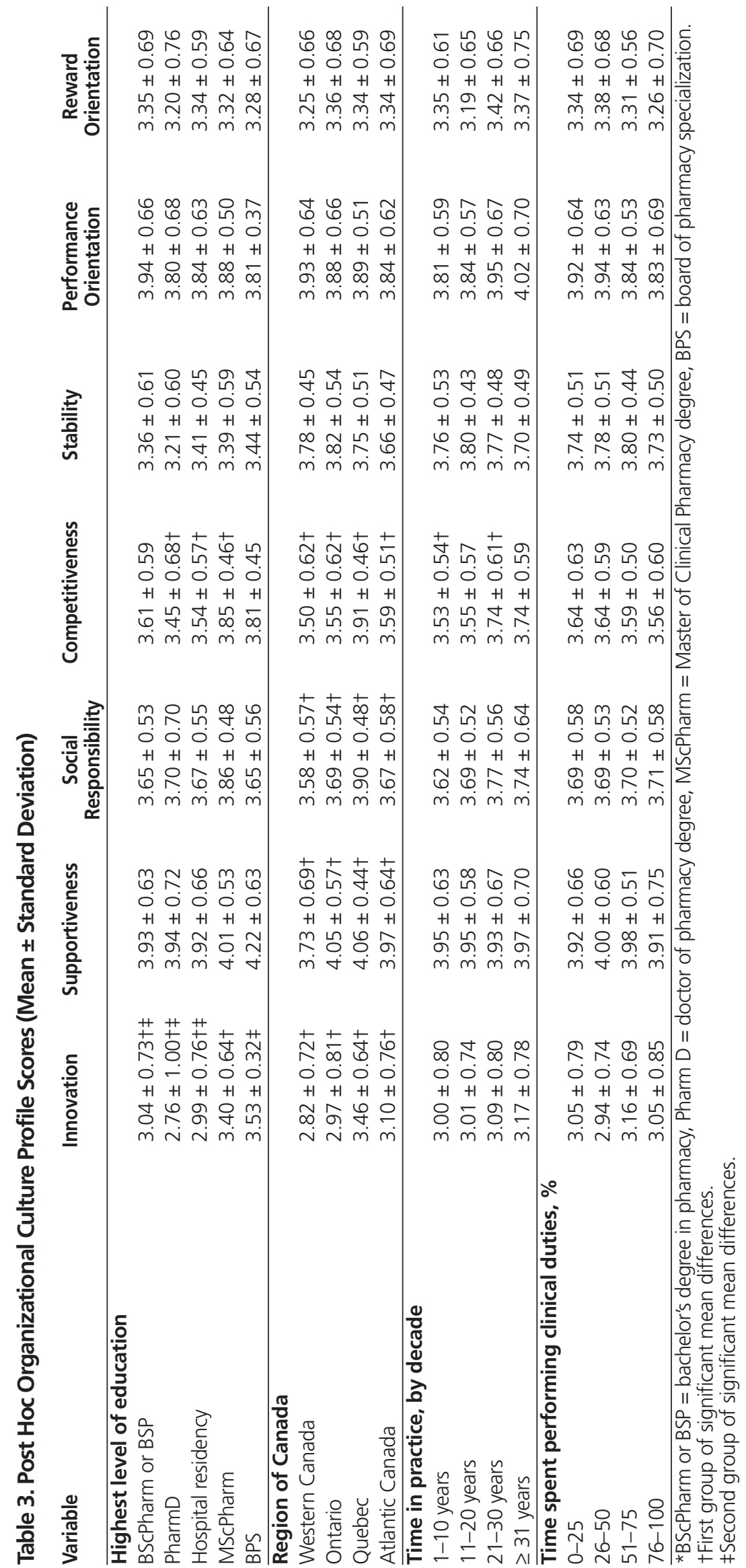


This single copy is for your personal, non-commercial use only.

For permission to reprint multiple copies or to order presentation-ready copies for distribution, contact CJHP at cjhpedit@cshp.ca

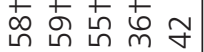
$\begin{array}{lllll}0 & 0 & 1 \\ 0 & 0 & 0 & 0 & 0 \\ +1 & +1 & +1 & +1 & +1\end{array}$

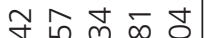
$m m i n$

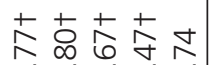
$\begin{array}{lllll}0 & 0 & 0 & 0 & 0 \\ 0 & 0 & 0\end{array}$

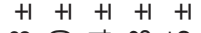

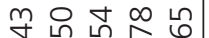
iñ i i i

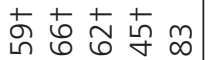
$\begin{array}{ccccc}0 & 0 & 0 & 0 & 0 \\ +1 & +1 & +1 & +1 & +1\end{array}$

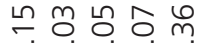
$\dot{\forall} \dot{\forall} \dot{\forall} \dot{m} m$

\section{.}

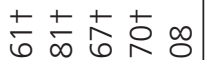

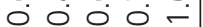
$\begin{array}{llll}2 & +1 & +1 & +1 \\ +1 & +1\end{array}$ ๖ $\forall \dot{m} \sim \dot{m}$

产孛勀卖品

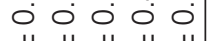

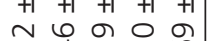
సิ 워 고유 m m $m \sim$

寺茄菂古 . $m \leqslant$

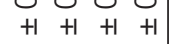
$\stackrel{\sim}{N} \tilde{m}=\stackrel{\infty}{m}$

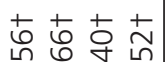
0000 $+1+1+1$ ถำ ㄴํㅇ m $\dot{\forall} \sim \dot{\forall}$

$m m \bar{n}$

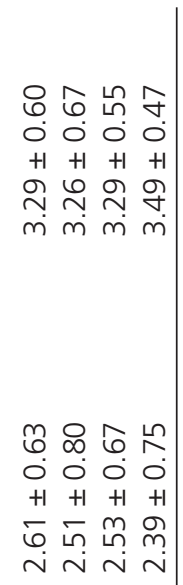

ก $\sim \sim$

மூ $\begin{array}{llll}0 & 0 & 0 & 0 \\ +1 & +1 & +1 & +1\end{array}$ 용쥬 mं mं m

必 万ু 000

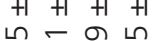
는 $m \dot{m} m$

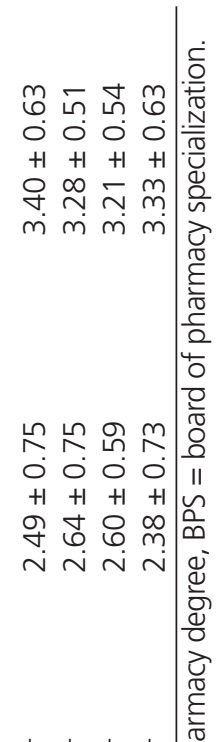

苍圭克图

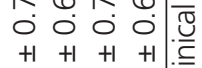
$8 \infty \approx m$ $\forall \dot{m} m \dot{q}$ प

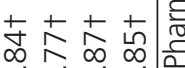
0.0000. $+1++1+1 \sum$

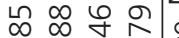
in m m $m$

$\bullet \bullet \overline{0}$ 0 o 00 o $+1+1+1+1$ $\simeq$ 능 용요 ₹ 0 के $m$ तोin

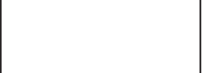

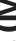


recent Hospital Pharmacy in Canada Report (for 2011/12) reveals that when provincial respondents are amalgamated into regions, as for the current study, the proportions of respondents were largely similar, with the exception of the Atlantic provinces, which were overrepresented in the current study (Western Canada 34\% in the Hospital Pharmacy in Canada Survey versus $27 \%$ in the current study, Ontario $29 \%$ versus 30\%, Quebec $26 \%$ versus $18 \%$, Atlantic Canada $11 \%$ versus $25 \%) .{ }^{43}$ Similarities were also noted between the samples in terms of number of years in practice.

A second limitation was the lack of back-translation of the French version of the survey instrument, to increase the internal validity. Third, it was difficult to separate the influence of the unique provincial culture of Quebec from influences that may relate specifically to subgroup differences within the profession of pharmacy. Fourth, to the best of the authors' knowledge, this is the first study within pharmacy to use both the Organizational Culture Profile and the Big Five Inventory in a population of pharmacists. As such, further research is required to more fully determine the applicability of these tools to this population. Finally, the use of surveys to study professional culture is problematic, because they utilize the phraseology of researchers and not that of members of the particular culture. ${ }^{18}$ Therefore, it would not be appropriate to suggest that this work has completely characterized the professional culture or personality traits of hospital pharmacists.

\section{CONCLUSION}

The results from this survey study provide initial insight into the professional culture and personality traits of Canadian hospital pharmacists, as well as the influence of a number of cultural antecedents on the manifestation of these cultural factors and personality traits. Despite the fact that the identified subgroup differences were small, they do suggest the need to reconsider the traditional approach to practice change within the profession. More specifically, greater attention must be paid to the local context in which changes are proposed. Moreover, future research ought to be designed to mirror that examined in a literature review in which the personality traits of medical students and their subsequent performance in medical school were tracked. ${ }^{44}$ In particular, that review found that conscientiousness was highly correlated with medical school performance, with traits such as extraversion becoming more important in clinical environments. ${ }^{44}$ Gaining greater insight into the relationship between cultural factors and personality traits and the actual behaviours of pharmacists will prove invaluable for organizations like the Canadian Society of Hospital Pharmacists ${ }^{12}$ in developing tailored, context-specific approaches to practice change. ${ }^{13}$

\footnotetext{
References

1. Koshman SL, Charrois TL, Simpson SH, McAlister FA, Tsuyuki RT. Pharmacist care of patients with heart failure. Arch Intern Med. 2008;168(7):687-94.
}

2. Machado M, Bajcar J, Guzzo GC, Einarson TR. Sensitivity of patient outcomes to pharmacist interventions. Part I: Systematic review and metaanalysis in diabetes management. Ann Pharmacother. 2007;41(10):1569-82.

3. Machado M, Bajcar J, Guzzo GC, Einarson TR. Sensitivity of patient outcomes to pharmacist interventions. Part II: Systematic review and meta-analysis in hypertension management. Ann Pharmacother. 2007; 41(11):1770-81.

4. Machado M, Bajcar J, Guzzo GC, Einarson TR. Sensitivity of patient outcomes to pharmacist interventions. Part III: Systematic review and meta-analysis in hyperlipidemia management. Ann Pharmacother. 2008; 42(9):1195-207.

5. Charrois TL, Zolezzi M, Koshman SL, Pearson G, Makowsky M, Durec T, et al. A systematic review of the evidence for pharmacist care of patients with dsylipidemia. Pharmacotherapy. 2012;32(3):222-33.

6. Elias M, Burden A, Cadarette S. The impact of pharmacist interventions on osteoporosis management: a systematic review. Osteoporos Int. 2011; 22(10):2587-96.

7. Chisholm-Burns MA, Kim Lee J, Spivey CA, Slack M, Herrier RN, Hall-Lipsy EJ, et al. US pharmacists' effect as team members on patient care: systematic review and meta-analyses. Med Care. 2010;48(10):923-33.

8. Wubben DPV, Eva M. Effects of pharmacist outpatient interventions on adults with diabetes mellitus: a systematic review. Pharmacotherapy. 2008; 28(4):421-36

9. Task Force on a Blueprint for Pharmacy. Blueprint for pharmacy: implementation plan. Ottawa (ON): Canadian Pharmacists Association; 2009.

10. Tsuyuki RT, Schindel TJ. Changing pharmacy practice: the leadership challenge. Can Pharm J. 2008;141(3):174-80.

11. Task Force on a Blueprint for Pharmacy. Blueprint for Pharmacy: the vision for pharmacy. Ottawa (ON): Canadian Pharmacists Association; 2008.

12. CSHP 2015 - Targeting excellence in pharmacy practice. Ottawa $(\mathrm{ON})$ : Canadian Society of Hospital Pharmacists; 2014 [cited 2014 Feb 5]. Available from: www.cshp.ca/programs/cshp2015/

13. Kitson A, Harvey G, McCormack B. Enabling the implementation of evidence based practice: a conceptual framework. Qual Health Care. 1998; 7(3):149-58.

14. Kitson A, Rycroft-Malone J, Harvey G, McCormack B, Seers K, Titchen A. Evaluating the successful implementation of evidence into practice using the PARiHS framework: theoretical and practical challenges. Implement Sci. 2008;3:1.

15. Gerardi D. The culture of health care: how professional and organizational cultures impact conflict management. Ga State Univ Law Rev. 2005; 21(4):857-90.

16. Ginsburg L, Tregunno D. New approaches to interprofessional education and collaborative practice: lessons from the organizational change literature. J Interprof Care. 2005;19 Suppl 1:177-87.

17. Williams A, Sibbald B. Changing roles and identities in primary health care: exploring a cuture of uncertainty. J Adv Nurs. 1999;29(3):737-45.

18. Martin J. Organizational culture: mapping the terrain. Thousand Oaks (CA): Sage Publications; 2002.

19. Schein EH. Organizational culture. Am Psychol. 1990;45(2):109-19.

20. Livigni R. Occupational subcultures in the workplace. Clin Sociol. 1994;12(1):290-1.

21. Boutin-Foster C, Foster J, Konopasek L. Physician, know thyself: the professional culture of medicine as a framework for teaching cultural competence. Acad Med. 2008;83(1):106-11.

22. Burke L, Davies K. Introducing the special edition on occuational culture and skills in probation practice. Eur J Probat. 2011;3(3):1-14.

23. Hansen CD, Kahnweiler WM, Wilensky AS. Human resource development as an occupational culture through organizational stories. Hum Resour Dev Q. 1994;5(3):253-68.

24. Johnson SD, Koh HC, Killough LN. Organizational and occupational culture and the perception of managerial accounting terms: an exploratory study using perceptual mapping techniques. Contemp Manag Res. 2009; 5(4):317-42.

25. Hopkins A, Solomon J, Abelson J. Shifting boundaries in professional care. JR Soc Med. 1996;89(7):364-71.

26. Roberts CS. Conflicting professional values in social work and medicine. Health Soc Work. 1989;14(3):211-8.

27. Scott T, Mannion R, Marshall M, Davies H. Does organisational culture influence health care performance? A review of the evidence. J Health Serv Res Policy. 2003;8(2):105-17.

28. O'Reilly C, Chatman J, Caldwell D. People and organizational culture: a profile comparison approach to assessing person organization fit. Acad Manag J. 1991;34(3):487-516 
29. Cable DM, Judge TA. Interviewers' perceptions of person-organization fit and organizational selection decisions. J Appl Psychol. 1997;82(4):546-61.

30. Vandenberghe C. Organizational culture, person-culture fit, and turnover: a replication in the healthcare industry. J Organ Behav. 1999;20(2):175-84.

31. Sarros J, Gray J, Densten I, Cooper B. The organizational culture profile revisited and revised: an Australian perspective. Aust J Manag. 2005;30:159-82.

32. McCrae RR. Trait psychology and the revival of personality and culture studies. Am Behav Sci. 2000;44:10-31.

33. McCrae RR. Trait psychology and culture: exploring intercultural comparisons. J Personal. 2001;69(6):819-46.

34. McCrae RR, Terracciano A, al. e. Personality profiles of cultures: aggregate personality traits. J Personal Soc Psychol. 2005;89(3):407-25.

35. John O, Naumann L, Soto C. Paradigm shift to the integrative Big Five taxonomy: history, measurement and conceptual issues. New York (NY): Guilford Press; 2008.

36. Barrick M, Mount M, Gupta R. Meta-analysis of the relationship between the Five Factor Model of personality and Holland's occupational types. Pers Psychol. 2003;56(1):45-74.

37. Chong WW, Aslani P, Chen TF. Pharmacist-patient communication on use of antidepressants: a simulated patient study in community pharmacy. Res Soc Admin Pharm. 2012;10(2):419-37.

38. Hall J, Rosenthal M, Family H, Sutton J, Hall K, Tsuyuki R. Personality traits of hospital pharmacists: towrad a better understanding of factors influencing pharmacy practice change. Can J Hosp Pharm. 2013;66(5): 289-95.

39. Srivastava S, John OP, Gosling SD, Potter J. Development of personality in early and middle adulthood: set like plaster or persistent change? J Personal Soc Psychol. 2003;84(5):1041-53.

40. Eta-square. In: IBM knowledge center [website]. Armonk (NY): IBM; [cited 2014 Mar 18]. Available from: http://pic.dhe.ibm.com/infocenter/ spssas/v1r0m0/index.jsp?topic=\%2Fcom.ibm.spss.analyticcatalyst.help $\% 2 \mathrm{~F}$ analytic catalyst $\% 2$ Fetasquared.html

41. Field A. Discovering statistics using SPSS statistics. 3rd ed. Thousand Oaks (CA): Sage Publications; 2009.

42. Pharmacists in Canada. Ottawa $(\mathrm{ON})$ : Canadian Pharmacists Association; 2014 [cited 2014 Feb 5]. Available from: www.pharmacists.ca/index.cfm/ pharmacy-in-canada/pharmacists-in-canada/

43. Babich M, Bornstein C, Bussières JF, Doucette D, Hall K, Lefebvre P, et al., editors. Hospital pharmacy in Canada 2011/2012 report. Eli Lilly Canada; 2012 [cited 2014 Jul 7]. Available from: www.lillyhospitalsurvey.ca/hpc2/ content/rep_2012_toc.asp

44. Doherty EM, Nugent E. Personality factors and medical training: a review of the literature. Med Educ. 2011;45(2):132-40.
Meagen Rosenthal, PhD, is Assistant Professor in the Department of Pharmacy Administration, School of Pharmacy, University of Mississippi, University, Mississippi.

Kevin W Hall, BSCPharm, PharmD, FCSHP, is Clinical Associate Professor in the Faculty of Pharmacy, University of Alberta, Edmonton, Alberta.

Jean-François Bussières, BPharm, MSC, MBA, FCSHP, is Head of the Department of Pharmacy and the Pharmacy Practice Research Unit, Centre hospitalier universitaire Sainte-Justine, and Clinical Professor in the Faculty of Pharmacy, Université de Montréal, Montréal, Quebec.

Ross T Tsuyuki, BSC(Pharm), PharmD, MSC, FCSHP, FACC, is a Professor of Medicine (Cardiology) and Director, EPICORE Centre, Faculty of Medicine and Dentistry, University of Alberta, Edmonton, Alberta.

Competing interests: Ross Tsuyuki serves on the BMS-AstraZeneca Advisory Board for Access with Evidence Development programs; serves as a consultant and Pharmacy Advisory Board member for PharmaSmart International; serves as a consultant for Merck; serves on the advisory board for the MAVIKontrol patient support program sponsored by Abbott; has received institutional grants from Sanofi and AstraZeneca for investigator-initiated trials; and serves as a member of the Boehringer Ingelheim data monitoring board for dabigatran studies. Kevin Hall served as a managing editor and Jean-François Bussières as an editor for the 2011/2012 Hospital Pharmacy Survey and Report (supported by Eli Lilly Canada). Kevin Hall also receives an honorarium and travel expenses from Pharmaceutical Partners of Canada and Eli Lilly Inc. for presentations dealing with sterile compounding and the future of hospital pharmacy practice. No competing interests declared by Meagen Rosenthal.

\section{Address correspondence to:}

Dr Meagen Rosenthal

Department of Pharmacy Administration

School of Pharmacy

University of Mississippi

223 Faser Hall

Post Office Box 1848

University MS 38677-1848 USA

e-mail: mmrosent@olemiss.edu

\title{
几 Canadian Society of Hospital Pharmacists Société canadienne des pharmaciens d'hôpitaux
}

\author{
Membership Year 2015/2016 \\ (July I, 2015 - June 30, 2016)
}

Are you a Member or Supporter of the Canadian Society of Hospital Pharmacists?

CSHP has celebrated 67 years of inspiration and leadership among a growing network of over 3000 pharmacy colleagues. When you join CSHP, you have access to resources and opportunities that will enhance your career and help influence healthcare in Canada. Thank you for your participation in CSHP 2015, an initiative challenging all pharmacists to improve patient medication outcomes and safety through advancing pharmacy practice excellence by the year 2015 .

Renew or join today!

Membership Enquiries: Please contact Membership Services

Tel.: (613) 736-9733 Ext. 222 | Fax: (613) 736-5660 | Email: membershipservices@cshp.ca

$$
\text { www.cshp.ca } 1000
$$

